\title{
Management factors affecting densities of common grassland birds of high elevation grasslands of eastern South Africa: Ingula as a case study
}

\author{
David H. Maphisa ${ }^{1,2^{*}}$, Hanneline Smit-Robinson ${ }^{3,4}$, Les G. Underhill ${ }^{5}$ and Res Altwegg ${ }^{2,6}$
}

\begin{abstract}
Background: World-wide grassland birds are in decline due to habitat loss and degradation resulting from intensive agricultural practices. Understanding how key grassland habitat attributes determine grassland bird densities is required to make appropriate conservation decisions. We examine drivers of bird densities in a South African grassland area that has been managed for biodiversity conservation with reduced grazing pressure.
\end{abstract}

Methods: We estimated the density of the eight most common grassland bird species encountered in our area to evaluate the effects of recent grassland management changes on the avifauna. We collected data on birds and habitat from the austral summers of 2006/2007, 2007/2008 and 2010/2011. We used hierarchical distance sampling methods to estimate density of birds relative to two main habitat variables, i.e., grass cover and height. In addition, we used regression splines within these distance sampling models as a more flexible description of suitable ranges of grass height and cover for each species.

Results: For most species, density is related to grass height and cover as expected. The African Quailfinch (Ortygospiza atricollis) and Common Quail (Coturnix coturnix) preferred relatively short and open grass. The Yellow-breasted Pipit (Anthus chloris), African Pipit (Anthus cinnamomeus) and Red-capped Lark (Calandrella cinerea) preferred short and relatively dense grass, while the Wing-snapping Cisticola (Cisticola ayresii) preferred grass of intermediate height and cover. The Cape Longclaw (Macronyx capensis) and Zitting Cisticola (Cisticola juncidis) preferred tall and dense grass. Our results agree with previous studies that grass height combined with grass cover are the most important habitat features that managers should manipulate in order to increase the density of target species. The regression splines show that the effect of these two habitat variables on density is well described by linear relationships for most species.

Conclusions: This study supports previous studies suggesting that grazing and fire are important tools for management to use in order to create a mosaic of grass height and cover that would support high densities of desired species. We suggest that conservation managers of these grasslands combine fire and grazing as management tools to create suitable habitats for grassland birds in general.

Keywords: Density and detection, Grassland birds, Grass height and cover, Hierarchical distance sampling models

\footnotetext{
*Correspondence: maphisad@gmail.com

1 South African National Biodiversity Institute, Private Bag X7,

Claremont 7735, South Africa

Full list of author information is available at the end of the article
} 


\section{Background}

Globally, the grassland biome and associated species are threatened and require management interventions to prevent further habitat loss and species extinction (With et al. 2008; Ceballos et al. 2010; Richardson et al. 2014). In southern Africa, grasslands are also one of the most threatened biomes, with $23 \%$ under cultivation, $60 \%$ irreversibly transformed, $2 \%$ formally protected and most of the remaining natural areas used as rangeland for livestock (Fairbanks et al. 2000; Reyers et al. 2001; O'Connor and Kuyler 2009). An assessment of conservation priorities in the Grassland Biome in southern Africa identified 36.7\% of the biome as being important for biodiversity conservation (Egoh et al. 2011). In particular, South Africa's moist grasslands harbor globally significant biodiversity, supply essential ecosystem services, support crop and livestock, forestry and settlement, yet are poorly conserved (O'Connor and Kuyler 2009). This area also coincides with high avifaunal species richness, diversity and endemism (Maphisa et al. 2016). As a result, a number of Important Bird and Biodiversity Areas (IBAs) have been proclaimed in the area (e.g. Barnes 1998). Despite this, only a few studies (e.g. Mentis and Bigalke 1981; Jansen et al. 1999) have examined abundance or densities of bird species in relation to habitat features that can be managed. Regionally, fire is an important conservation management tool used both on private and state lands to make habitats suitable for birds (Parr and Chown 2003). In addition to heavy livestock grazing and other agricultural activities, this area is a target for energy development projects to meet growing human demand for electricity and water for consumption (Maphisa et al. 2016).

Basing conservation decisions on reliable density estimates is critical to halt current species habitat loss and species extinction (Wintle et al. 2005; Post van der Burg et al. 2011). However, estimating population densities of animals is notoriously difficult because some animals remain undetected during surveys (Diefenbach and Brauning 2003). Many grassland bird species look alike and are therefore difficult to identify in the field. Furthermore, the detection probability varies across methods and different observers, changes with habitats and weather conditions (Petitot et al. 2014). Hierarchical distance-sampling methods account for the detection process and are therefore commonly used to study animal density (Marques et al. 2007; Oedekoven et al. 2013). Improvements in distance sampling allow for the incorporation of environmental and habitat variables to fully explore variation in density of species across sites (Royle et al. 2004; Thomas et al. 2010).

Hierarchical distance sampling models consist of two components (Fiske and Chandler 2011; Sillett et al. 2012): the first component models the observation process (detection probability as a function of distance from the transect line) and the second models the biological process (density of the focal bird species). The observation model involves the choice of a distance function whose parameters will be estimated from the data. This approach has recently been used to relate density of birds to habitat variables within Fynbos Vegetation in South Africa (Lee et al. 2015) but has not been used within high-elevation grasslands of southeastern Africa. We present density estimates based on hierarchical distance sampling models for common bird species in relation to vegetation attributes at Ingula, a high-elevation grassland in eastern South Africa which will soon be declared a nature reserve (Maphisa 2012).

Few studies examine how habitat and management actions affect bird densities at high-elevation grasslands of eastern South Africa. The few studies that exist, examine the effect of burning and grazing on a single species (Parr and Chown 2003) and do not account for the observation process (e.g. Jansen et al. 1999; Little et al. 2013). Burning is the main management tool in agricultural lands and conservation areas in this region (Parr and Chown 2003). Some studies indicate that inappropriate use of fire and grazing leads to degradation of grasslands in this region (Maphisa et al. 2009, 2016; Little et al. 2015a).

We relate grass height and cover in summer to eight small grassland birds that we found to be the most common during preliminary data analysis. Summers coincide with breeding for most birds and is the period with the highest species richness in this area (Maphisa et al. 2016). We used the following eight species: Cape Longclaw (Macronyx capensis), Wing-snapping Cisticola (Cisticola ayresii), African Pipit (Anthus cinnamomeus), African Quail Finch (Ortygospiza atricollis), Yellow-breasted Pipit (Anthus chloris), Red-capped Lark (Calandrella cinerea), Zitting Cisticola (Cisticola juncidis) and Common Quail (Coturnix coturnix). Of these, only the Yellow-breasted Pipit is threatened nationally (Taylor et al. 2015). Conservation managers often rely on surrogates to estimate biodiversity to manage habitat for other species whose density cannot be estimated by distance sampling because they are rare (Nally and Fleishman 2004; Mattsson and Marshall 2009; Lewandowski 2010). Because the suite of species we chose to study represents a range of different habitat requirements in terms of their responses to grass height and cover, we suggest that they can be used as indicators to monitor habitat suitability for rare threatened species which are of conservation concern.

\section{Methods}

\section{Study site}

The study site is situated c. $23 \mathrm{~km}$ northeast $\left(28^{\circ} 14^{\prime} \mathrm{E}\right.$, $29^{\circ} 35^{\prime}$ S) of the hamlet town of Van Reenen covered by 
moist-high elevation grasslands typical of eastern South Africa. It is the site of the Eskom Ingula Pumped Storage Scheme (Ingula or IPSS), the main purpose of which is to augment electricity to the national grid during periods of peak consumption demand (Maphisa et al. 2016).

Ingula has an area of about 8000 ha and falls within the two provinces KwaZulu-Natal (KZN) and the Free State (FS). The average elevation on the FS site is 1700 $\mathrm{m}$ asl compared to $1200 \mathrm{~m}$ asl on the KZN site. The FS site is dominated by sweet and sour grasslands, while the lower-lying grasslands on the KZN site is dominated by Cymbopogon-Hyrpochloa-Hyperrhinia sp. Of the natural vegetation type on the FS site $39 \%$ is exposed to combined land cover threats of degradation and the effects of transformation and roads (Reyers et al. 2001; Mentis 2014), while the KZN site is degraded and mostly invested by alien tree plantations (Maphisa 2015).

The FS side of the study area is viewed as particularly important because of the presence of an Important Bird and Biodiversity Area (SA IBA 043), with the Bedford-Chatsworth Wetland at its center (Barnes 1998; Marnewick et al. 2015). Of the two sites, the lower site is therefore of reduced conservation value and has been used for above-ground infrastructures of the power station. To compensate for the part of the wetland that has been transformed into a storage dam on the FS side, additional land was bought and set aside for conservation. The overall goal of the new management is to declare this area as a nature reserve (Maphisa 2012) with conservation of birds as one of its conservation priorities.

Despite a relatively short distance separating the two sides, there are marked changes in temperature and rainfall (Maphisa et al. 2016). Most of the rainfall occurs during the summer months (October to February) with mean annual amounts of $1000 \mathrm{~mm}$ (Mentis 2014). The habitats at Ingula and surrounding grasslands are degraded due to heavy livestock grazing and annual fires in the past (Mentis 2006; Cauldwell 2012). Based on the perceived deterioration of the habitat resulting from years of heavy grazing and annual fires, an impact assessment report (Mentis 2006) recommended that livestock be replaced with game and recommended a minimum fire return period of 2 years. During the summer of $2005 / 2006$, cattle that belonged to private farmers were removed so that the habitat could recover from unsuitable past farming practices. This period coincides with the construction of the Pumped Storage Scheme, the primary purpose for which the land was bought. The Ingula management set aside additional land with the primary aim of managing the area to protect surrounding ecosystems and biodiversity (Maphisa 2015). However, a relatively small number of livestock belonging to tenants, were left behind by previous land owners pending a resettlement plan. The delay to move the tenants to alternative areas has resulted in management challenges to implement burning and grazing regimes to the full as per Mentis (2006) recommendations (Maphisa et al. 2016). Although much reduced, grazing happened everywhere and anytime during the course of our study. Fires of unknown origin consumed most of the study area on an annual basis.

\section{Bird sampling}

Using 1:50,000 topographic maps, we laid random transects of $500 \mathrm{~m}$ across the study area perpendicular to farm tracks, separated by $2 \mathrm{~km}$, avoiding too steep, rocky or transects lying adjacent to wetlands. We found 35 transects to be suitable for bird surveys because they had similar topography and were dominantly grassland. We surveyed birds along three fixed $50 \mathrm{~m}$ band transects from the center of the transect on both sides of the observer (Bibby et al. 2000; Buckland et al. 2001; Thomas et al. 2010) on all the transects, once per season (winter, spring, summer and autumn) (Maphisa et al. 2016). Strip transects is one of the most commonly used methods to estimate bird abundance, species habitat preferences and species richness for large-scale monitoring programs (e.g. Carrascal et al. 2009). All transect surveys were conducted by one person (DHM), mostly during early mornings (07:00-11:00) or mid-afternoons (15:00-16:00), when birds were most likely to be active (e.g. Maphisa et al. 2009). We extended bird surveys only to afternoons when logistic factors such as unsuitable weather prevented us from completing the survey on time in the mornings. But for such later surveys we selected a narrow time frame (15:00-16:00). We carried out bird surveys under stable weather conditions with good visibility.

In this study, we made use of birds and vegetation surveys for the following three summers: 2006/2007, $2007 / 2008$ and $2010 / 2011$. These periods coincide with the time when most species are on site and breeding (Maphisa et al. 2016). Only seventeen of the original total transects were surveyed during the summer of 2010/2011 due to time constraints. No survey was carried out during the summer of 2009/2010 because DHM was delegated to different types of surveys still on site.

\section{Measurements of vegetation and land cover variables}

Vegetation at each transect was surveyed immediately following the bird survey (e.g. Marx et al. 2008), using a $30 \mathrm{~cm}$ by $30 \mathrm{~cm}$ light metal frame divided into nine equal squares (Maphisa et al. 2009, 2016). The grid was thrown twice (at random) every $100 \mathrm{~m}$ along the $500 \mathrm{~m}$ transects. At each throw we recorded how many of the nine squares fell on grass, bare soil, dead grass, forbs or 
stones. Vegetation height was recorded at every corner of the frame, at each throw point using a measuring tape. The four measurements were averaged for data analysis. Intensity of grazing along each transect was categorized independently of measured grass height and cover as none, light or heavily grazed, based on signs of habitat trampling by animals, visual bare ground cover or grass height. Given the variability in fire timing and intensity across the study area, each transect was simply classified into one of two categories: burned or unburned prior to the survey.

\section{Data analysis and fitting the model}

Distance sampling is a widely used technique for estimating the density of biological populations (e.g. Bibby et al. 2000; Buckland et al. 2001; Thomas et al. 2005, 2010). Within transect-based distance sampling, the observer records individuals at perpendicular distances away from the line of observation. One of the first steps in the analysis of distance sampling data is modelling the probability of detection (e.g. Thomas et al. 2010). Distance sampling models assume that individuals at zero distance from the line are observed with certainty (Thomas et al. 2010; Weller et al. 2012) and that the chances of detecting an individual decreases with increasing distance away from the observer (Speed et al. 2010; Weller et al. 2012). Improvements in distance sampling offer the opportunity to model both the observation process and density as a function of covariates (Marques et al. 2007; Weller et al. 2012). Rigorous statistical techniques have been developed to account for decreasing probability of detection away from the observer, allowing density or abundance to be estimated more accurately, based on the decrease in the number of observed individuals away from the transect line (Speed et al. 2010; Thomas et al. 2010).

Function 'distsamp' in a package 'unmarked' (Fiske and Chandler 2011) in R version 2.15.1 (R Development Core Team 2013) was used to fit distance sampling models and to estimate the detection and density of the eight common grassland bird species. For each species, a half-normal detection function was used (Fiske and Chandler 2012). This was chosen by visually comparing the distribution of detections against the fitted function. Other commonly used distance functions were tested with similar results. We considered a number of survey variables that could potentially influence detection (e.g. Alexander and Hepp 2014) and how quickly the detection probability declines with increasing distance away from the transect line (Broekema and Overdyck 2012; Weller et al. 2012). These variables were the intensity of grazing along each transect per survey (none, light or heavy), whether there were visible signs of burning that year prior to the survey (burned or unburned), as well as grass height and cover along each transect.

\section{Model selection}

The primary use of habitat modelling in conservation planning is to predict the spatial distribution of suitable habitats for species of interest in a landscape (Martin et al. 2010; Wintle et al. 2005). We constructed six competing detection models with the above habitat variables of our interest. The first model assumed detection was similar across all the survey transects (Null model). The second and third models tested the effect of grazing and burning individually. Next we assumed that our ability to detect species could be determined by grass height alone or grass cover alone (fourth and fifth models). Our last model combined grass height and grass cover assuming that both variables might have a combined effect on species detection or use of habitat.

We used model selection, based on Akaike's Information Criterion (AIC) (Burnham and Anderson 2002; Mellin et al. 2010), to choose the best detection model out of the list of six competing models for each species. We considered the model with the lowest AIC value as the best model describing species detection (Taillie et al. 2015; Maphisa et al. 2016). To estimate the effect of grazing and burning on density of each species we used the best detection model above (Additional file 1: Appendix S1) to create a set of eight candidate models (Additional file 2: Appendix S2).

\section{Effect of grass height and cover on density of birds}

Our major focus was on how bird densities were related to grass cover and height because these are the two key habitat variables that determine habitat use by grassland birds (e.g. Fisher and Davis 2010). We first considered linear (on a log scale) relationships between density and grass height and cover. Then, we also used regression splines with two knots to fit more flexible relationships and to provide a more accurate prediction of species response to grass height and grass cover. Our implementation of regression splines follows that of Crainiceanu et al. (2005), where a basic function is calculated for each knot; these functions are then included as additive terms in a linear model.

\section{Results}

The number of detections (shown in brackets) per species differed amongst species. We found the following species: Cape Longclaw (184), African Pipit (109), Wing-snapping Cisticola (106), Yellow-breasted Pipit (70), Zitting Cisticola (65), Common Quail (60), African Quailfinch (36) and Red-capped Lark (33). For most species, the best detection function depended on habitat variables, implying that grass height and cover affected our ability to detect individual birds (Table 1). In particular, the model that combined grass height plus cover best explained 
Table 1 Summary of the results of model selection analysis to identify the best detection model for eight grassland bird species at Ingula, South Africa

\begin{tabular}{lllllrrrrr}
\hline & Detection models & CLC & WSC & AP & AQF & YBP & RCL & ZC & CQ \\
\hline 1. & dens(.)p(.) & 4.08 & 7.35 & 6.00 & 14.41 & 9.71 & 13.36 & 10.26 & 1.49 \\
2. & dens(.)p(Burning) & 0.00 & 5.47 & 7.84 & 16.37 & 6.50 & 2.71 & 6.68 & 0.97 \\
3. & dens(.)p(Grazing) & 6.41 & 9.13 & 9.24 & 3.81 & 10.22 & 0.00 & 4.80 & 4.26 \\
4. & dens(.)p(cover) & 4.15 & 8.63 & 7.58 & 9.94 & 10.00 & 7.34 & 12.26 & 2.46 \\
5. & dens(.)p(avh) & 6.08 & 0.00 & 1.70 & 16.19 & 5.13 & 13.45 & 4.24 & 0.00 \\
6. & dens(.)p(avh + cover) & 5.37 & 1.58 & 0.00 & 0.00 & 0.00 & 6.08 & 0.00 & 2.64 \\
\hline
\end{tabular}

The table shows delta AIC values, i.e., the difference in AIC between a particular model and the best. The fitted models are hierarchical distance sampling models and full model selection details are given in Additional file 1: Appendix S1. The best detection model for each species based on lowest delta AIC is highlighted in italics. Density dens(.) was held constant while considering the effects of transect habitat on the detection function p(.). The habitat variables were grass cover ('cover'), grass height ('avh') and whether the area had been grazed ('Grazing') or burned ('Burning') prior to the survey. Species are sorted from the most common (left) to least common (right); Cape Longclaw (CLC), Wing-snapping Cisticola (WSC), African Pipit (AP), African Quailfinch (AQF), Yellow-breasted Pipit (YBP), Red-capped Lark (RCL), Zitting Cisticola (ZC) and Common Quail (CQ)

the detection of four out of eight species (Table 1). Correcting for these effects, we then examined how grazing, burning, grass height and grass cover affected the density of the eight species differently (Table 2; Figs. 1, 2, 3, 4, 5, 6).

For Zitting Cisticola, Cape Longclaw, Red-capped Lark and African Quailfinch, the model allowing for different densities between transects that differed in how they were grazed (Model 3, Table 2) was slightly better supported by the data than the constant model (Model 1, Table 2), even though it was not the best supported model for any species. Zitting Cisticolas tended to occur at higher densities on heavily grazed transects than on ungrazed ones (Fig. 1), while the Cape Longclaw occurred at its lowest density on heavily grazed transects (Fig. 1). Red-capped larks occurred in their highest densities on lightly grazed transects where African Quailfinches had the lowest densities (Fig. 1).

For the Wing-snapping Cisticola and Yellow-Breasted Pipit, the model allowing densities to vary between burned and unburned transects (Model 2, Table 2) was the best model, while for Cape Longclaw, African
Quailfinch, Red-capped Lark and Common Quail, this model was better than the constant model (Model 1, Table 2). These species were more abundant on burned transects, except for Red-capped Larks, which were more abundant on unburned transects (Fig. 2).

For all species, one of the models involving grass height or cover (Models 4-8, Table 2) was better supported than the constant model (Model 1, Table 2). Model 6, allowing density to vary with both grass height and cover was clearly the best model for the African Pipit, African Quailfinch and Red-capped Lark. For Cape Longclaws Model 5, including only grass height, was the best even though several of the other models were close competitors for this species. For the Zitting Cisticola, the best model was Model 4 assuming a linear effect of grass cover on density. The Common Quail was the only species for which density was best described by a model that included a nonlinear relationship, Model 8, with a regression spline for cover. Overall, all eight species responded differently to the effect of increasing grass height and grass cover (Figs. 3, 4, 5, 6). Of these species, Cape Longclaws apparently benefitted from little grazing with their

Table 2 Summary of model selection analysis (see Additional file 2: Appendix S2 for full details) used to estimate the density of eight common grassland bird species at Ingula in relation to grazing, burning, grass height and grass cover

\begin{tabular}{lllrrrrrrr}
\hline & Density models & CLC & WSC & AP & AQF & YBP & RCL & ZC \\
\hline 1. & dens(.) & 2.72 & 18.36 & 26.61 & 15.93 & 24.24 & 8.81 & 22.78 & 8.03 \\
2. & dens(Burning) & 2.20 & 0.00 & 28.40 & 11.87 & 0.00 & 5.86 & 24.08 & 7.12 \\
3. & dens(Grazing) & 0.34 & 19.34 & 30.46 & 13.56 & 24.26 & 6.38 & 18.26 & 8.29 \\
4. & dens(Cover) & 0.11 & 20.13 & 24.86 & 6.03 & 26.23 & 8.25 & 0.00 & 8.09 \\
5. & dens(avh) & 0.00 & 20.27 & 11.93 & 17.83 & 16.84 & 5.58 & 43.39 & 7.05 \\
6. & dens(avh + cover) & 0.55 & 22.09 & 0.00 & 0.00 & 16.55 & 0.00 & 12.60 & 8.29 \\
7. & dens(s(cover)) & 1.71 & 8.24 & 30.53 & 4.82 & 23.17 & 21.58 & 24.94 & 0.00 \\
8. & dens(s(avh)) & 0.73 & 3.59 & 21.01 & 35.61 & 22.31 & 20.08 & 3.93 & 6.95 \\
\hline
\end{tabular}

For each species the detection function was modeled as in the best model in Table 1 . The relationship between density and grass height and cover was modeled as linear (on the log scale) relationships (avh and cover) and using regression splines with two knots [s(avh) and s(cover)]. See notes to Table 1 for more detail 

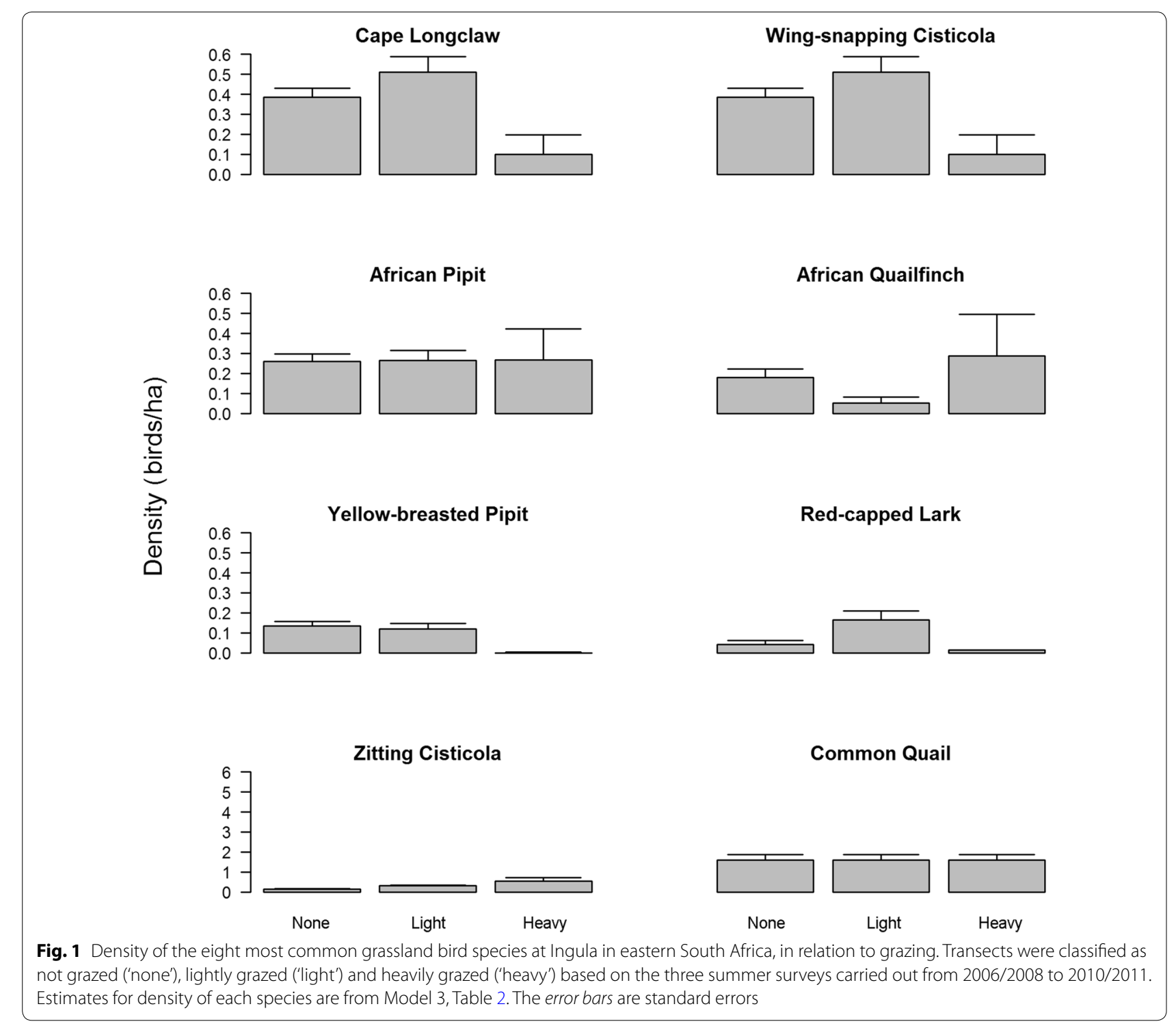

density increasing with increases in grass height and grass cover (Fig. 3). The Wing-snapping Cisticola, African Quailfinch, Yellow-breasted Pipit, Red-capped Lark and Common Quail densities decreased with increasing grass height and grass cover (Figs. 3, 4, 5, 6). African Pipit densities increased with increasing grass cover (Fig. 4). On the one hand the densities of Zitting Cisticolas increased with an increase in grass cover and Common Quail densities clearly peaked at intermediate levels of grass cover (Fig. 6).

\section{Discussion}

Our results support previous findings that sometimes grassland birds co-occur with differing habitat requirements (Maphisa et al. 2009, 2016). Fire and grazing affect aboveground biomass differently (Richardson et al. 2014). Depending on the intensity of fire and grazing, heterogeneity of micro niches is created across the landscape that affects bird species densities differently. The impact of fire and grazing on landscape and habitat attributes has been well documented (Jacobs et al. 2012). Our study is the first in the region to examine how vegetation variables affect the density of birds in a hierarchical way that incorporates detection. Grazing and burning affect species differently depending on their functional groups or the preferences of individual species (Richardson et al. 2014; Mero et al. 2015; Maphisa et al. 2016). Under managed burning and grazing (e.g. Klug et al. 2010; Richardson et al. 2014; Mero et al. 2015) we expected species that prefer short grass to be more abundant on burned 


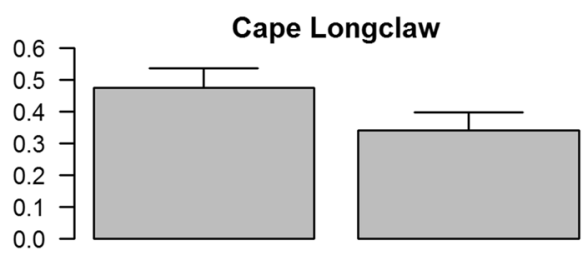

Wing-snapping Cisticola
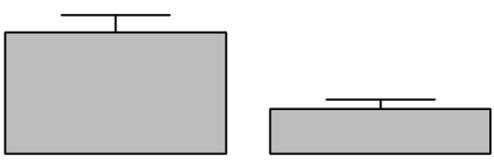

African Quailfinch
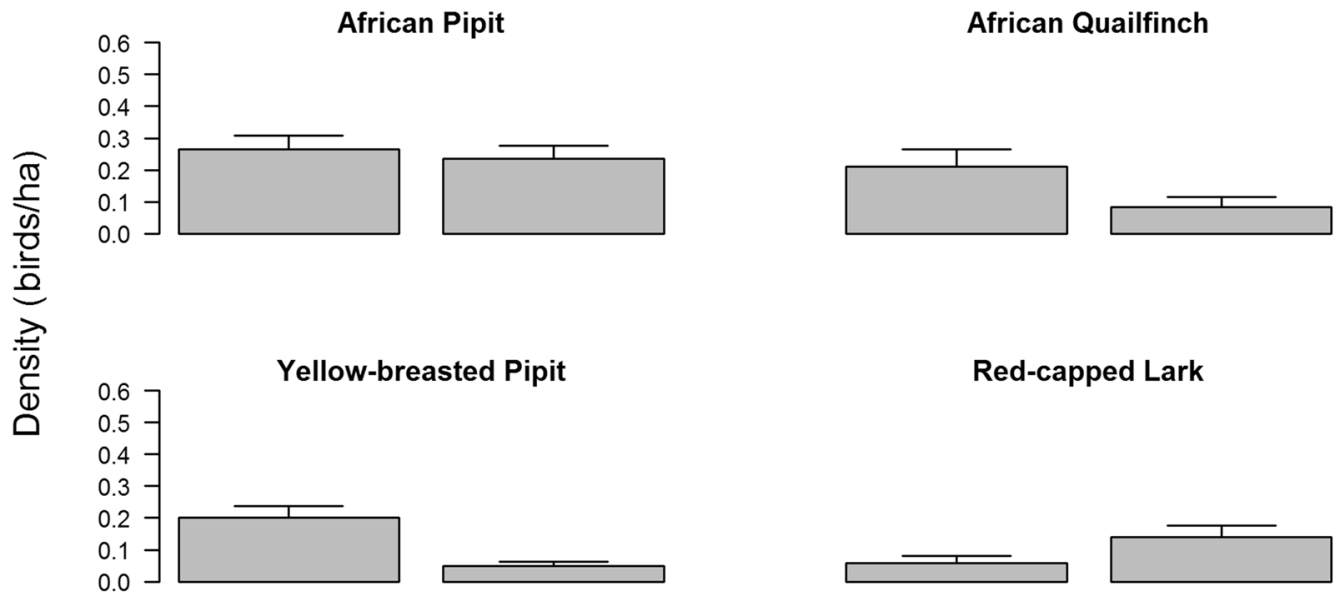

Red-capped Lark

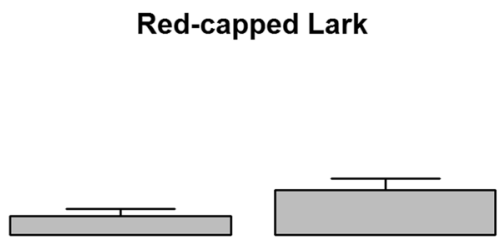

Common Quail

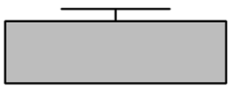

Burned

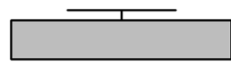

Not burned

Fig. 2 Density of the eight most common grassland bird species at Ingula in eastern South Africa, in relation to whether the grass along transects had been burned or not before the survey. Estimates for density of each species are from Model 2, Table 2. The error bars are standard errors

transects (e.g. Apfelbaum and Haney 1981) and thereafter with little grazing as it was at Ingula the density was expected to decrease with an increase in grass height. Most of the species we studied exhibited this with only two exceptions: both Cape Longclaws and Zitting Cisticolas increased in density with an increase in grass height (Figs. 3, 6). Because burning and grazing were not managed at our study site, we therefore expected grass height and cover to be better predictors of species density because of the ambiguity of visual classification of grazing in the field. For example, higher densities of Redcapped Larks and Common Quails (Fig. 2) on burned and unburned transects contradict our knowledge of habitat preferences for these two species. The same is true for the Common Quail which occurs in similar densities across the three categories of grazing (Fig. 1).
For three of the eight species we examined, we found that a combination of grass height and cover is more important than just grass height alone or grass cover alone. This agrees with previous findings that fire and burning complement each other to create habitats for birds (e.g. Fuhlendorf et al. 2009). Our study demonstrates that grass height and cover or each one alone, depending on the habitat requirements of individual species, determines habitat use by birds (Winter et al. 2005; Devereux et al. 2006; Donald et al. 2010). Regional studies that link species abundance to habitat do not take into account detection (e.g. Jansen et al. 1999; Little et al. 2013, 2015b). The same is true about the studies from north eastern African high-elevation grasslands (Mamo et al. 2016).

Grasslands habitat in our study area is mostly in its natural state other than for degradation from annual 


\section{Cape Longclaw}
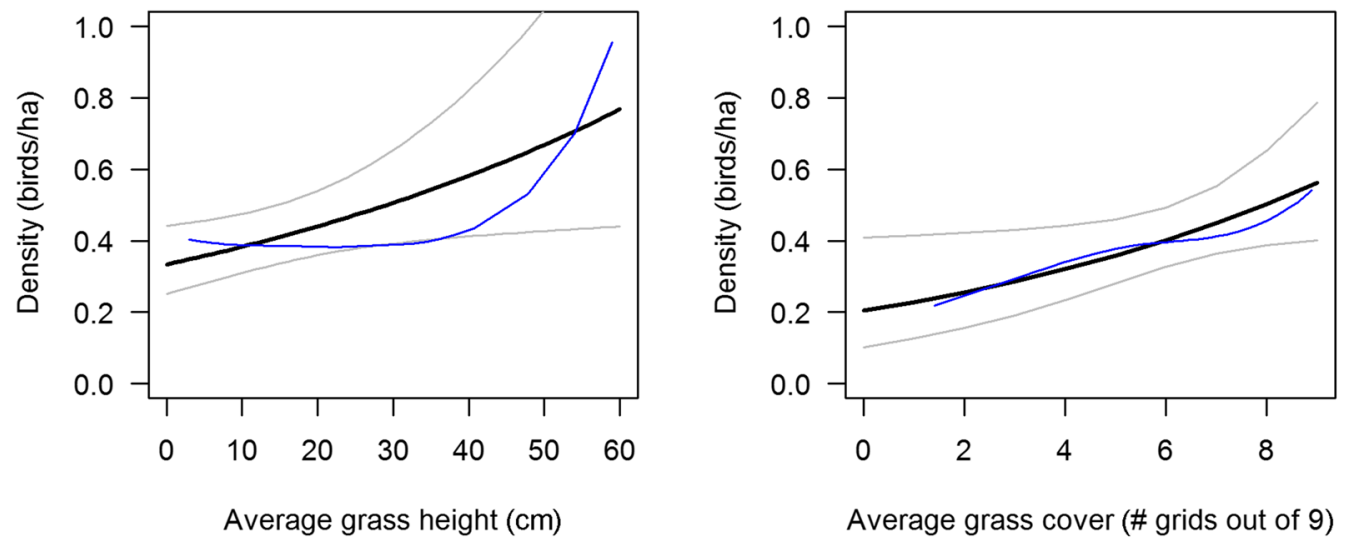

Wing-snapping Cisticola
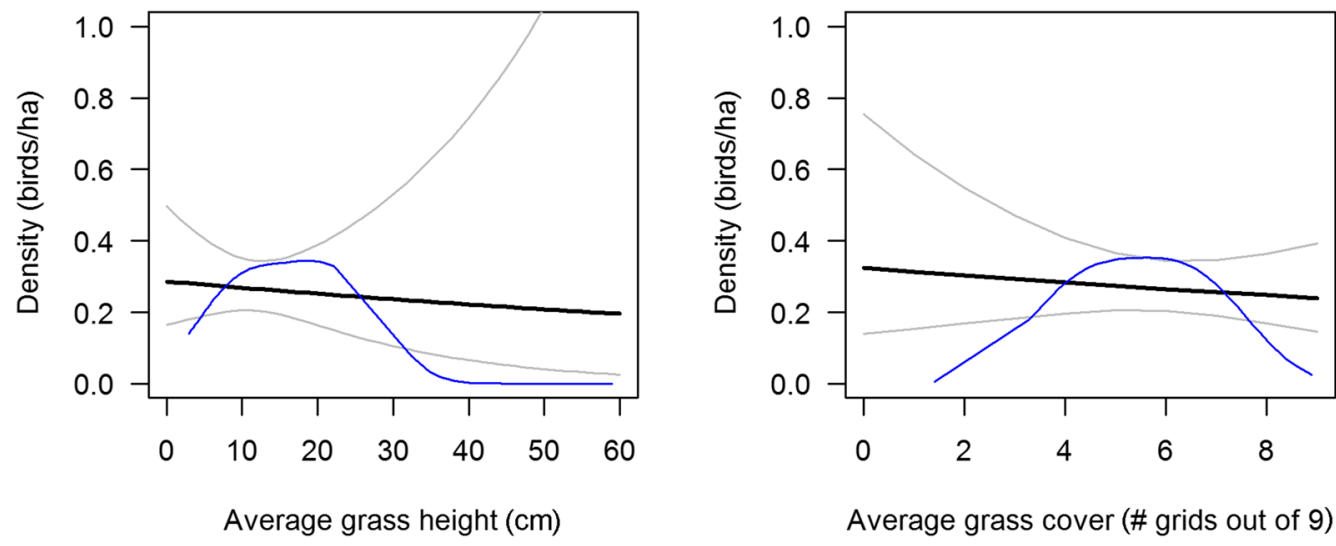

Average grass cover (\# grids out of 9)

Fig. 3 The effect of average grass height and cover on the habitat suitability of Cape Longclaw and Wing-snapping Cisticola at a high-elevation grassland in eastern South Africa. Light-grey lines are 95\% confidence intervals around the fitted response shape (black line) taken from models 7 and 8 in Table 2, while the blue lines are the best-fitting curves based on regression splines with two knots. Density estimates for grass height and cover are from Models 4 and 5 in Table 2

burning and heavy grazing. A similar study from northern Uruguay found that vegetation structure has variable effects on the density of grassland birds too (Azpiroz and Blake 2016). However, this study did not account for variability in detection because of insufficient sample size. To deal with problems of insufficient data some studies estimate relative densities (Post van der Burg et al. 2011). The study by Azpiroz and Blake (2016) mostly resembles our study because it includes natural grasslands, managed with cattle, game or sheep. Overall, Azpiroz and Blake (2016) found that bird numbers were more correlated with grass cover than with grass height in contrast to observations of Henslow's Sparrow (Ammodramus henslowii) at modified Missouri grasslands (e.g. Jacobs et al. 2012). But this is because the comparison of Azpiroz and Blake (2016) was made with croplands where vegetation height tends to be higher but sparse. Also the definition of grass cover for these two studies includes forbs or shrubs. In our study we excluded forbs in our analysis because of sparse forb data.

As expected in our study area, the African Quailfinch indicated steeper density declines with increasing grass cover than with grass height. This species is associated more with croplands than with natural grasslands (Kosicki et al. 2014; Maphisa 2015). Cape Longclaws, the most common species in a group, benefitted from little grazing in our study area with their density rising with increasing grass height and grass cover. Our results contradict Mamo et al. (2014) where a similar but endemic Abyssinian Longclaw (Macronyx flavicollis) occurred with higher densities in more open habitats. 


\section{African Pipit}

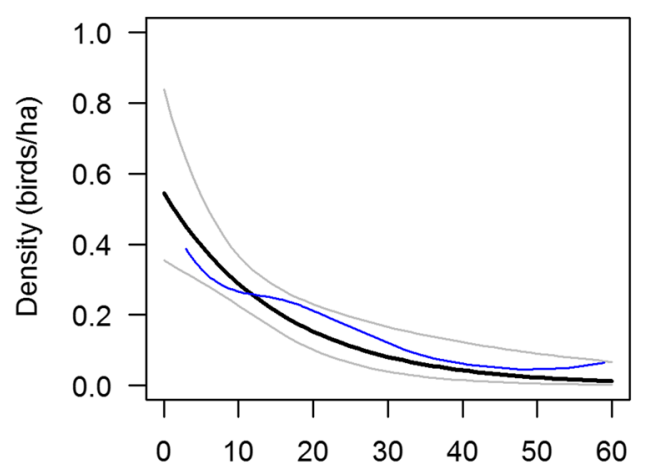

Average grass height $(\mathrm{cm})$

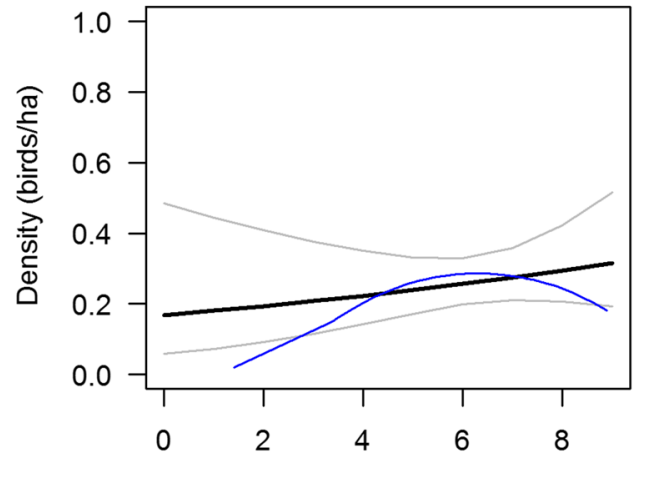

Average grass cover (\# grids out of 9)

African Quailfinch

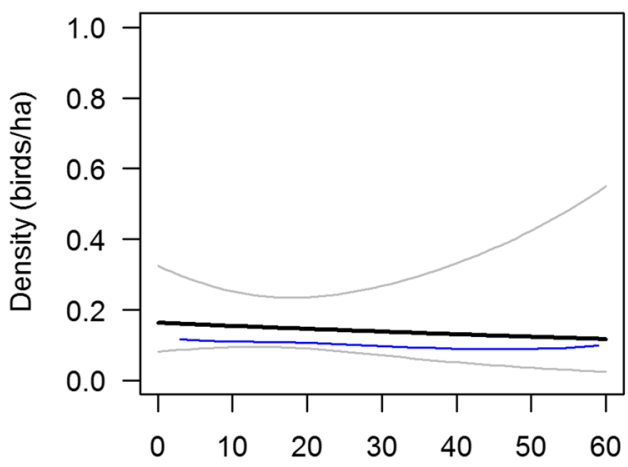

Average grass height $(\mathrm{cm})$

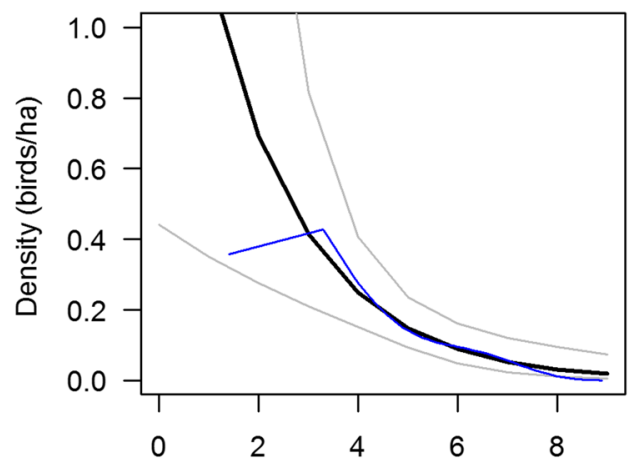

Average grass cover (\# of grids out of 9)

Fig. 4 Effect of average grass height and cover on the habitat suitability of African Pipit and African Quailfinch at a high-elevation grassland of eastern South Africa. See legend to Fig. 3 for details

Our results for the African Pipit (Fig. 4), a grassland generalist, agree with our knowledge of how this species reacts to changes in grass height and cover. The rising density of Zitting Cisticolas with increasing grass height agrees with the observation that this species requires high grass to breed (Maphisa 2015). The lowest densities of the threatened Yellow-breasted Pipit on heavily grazed transects (Fig. 1) may explain why this species is rare, given the widespread heavy grazing in the region (Maphisa et al. 2016). On the one hand the same species occurs in much higher densities on transects that were burned (Fig. 2) indicating a need for visual inspection of habitat (e.g. Maphisa et al. 2016). This makes sense given that in the case of our study area there was little grazing. Thick tall grass is worse than heavily grazed grass because of the possible effects of visual obstruction (e.g. Devereux et al. 2006). This is important for ground nesting birds that breed and feed on the ground.
The Common Quail is a regional local migrant with birds easily identified by call and sight early in the breeding season, when birds establish their territories. Birds are easy to see in the field at this time given widespread burning. But it will be harder to see or hear later in the season even when they are present because of increase in grass height and grass cover (Fig. 2) and that bird calls are less frequent. Alternatively, our study site could be a stopover with birds moving to areas that are intensively ploughed. Agricultural fields are a more suitable habitat for this species (Kosicki et al. 2014).

For most species in our study, grazing had no strong effect on density. However, this could be because there was little grazing on site to compare amongst categories of grazing. In contrast, a study with replicated control plots from mountainous grasslands in Norway (Loe et al. 2007) managed with sheep, found that the density of birds was much higher on farms with high sheep densities. But 


\section{Yellow-breasted Pipit}

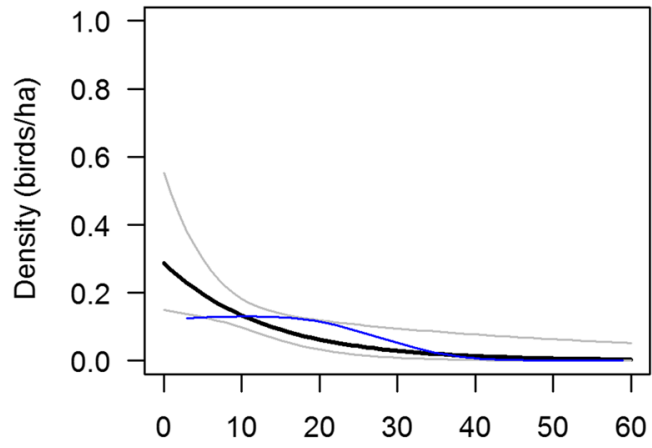

Average grass height $(\mathrm{cm})$

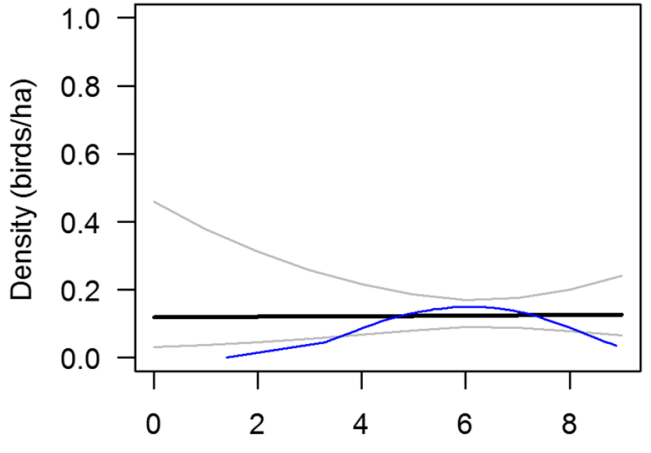

Average grass cover (\# grids out of 9)

\section{Red-capped Lark}
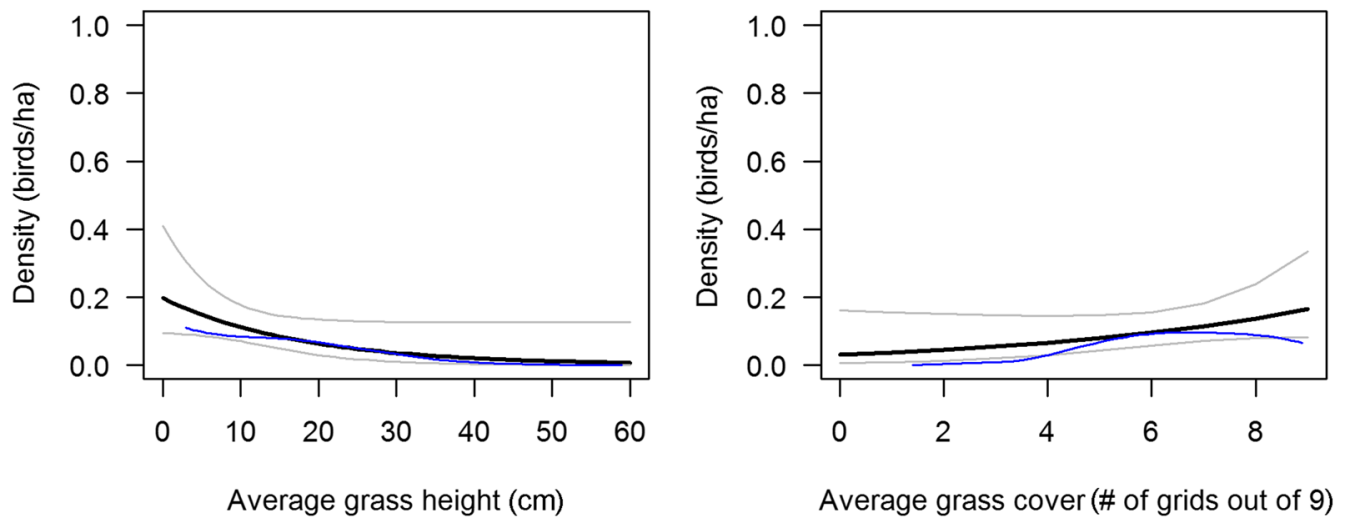

Fig. 5 Effect of average grass height and cover on the habitat suitability of Yellow-breasted Pipit and Red-capped Lark at a high-elevation grassland in eastern South Africa. See legend to Fig. 3 for details

high bird densities on heavily grazed grasslands do not necessarily indicate habitat suitability because this might simply indicate food availability (Loe et al. 2007) but may not support breeding.

Land set aside for conservation in our region is increasing in the form of private reserves and state owned lands. On these lands, we recommend that researchers implement the recommendations by Parr and Chown (2003) regarding experimental research on the effect of fire intensity, timing and variability across the landscape on fauna. A further consideration that needs to be taken into account is the number of replicates compared between sites that are managed differently (e.g. Parr and Chown 2003).
Most species of conservation concern are found on privately owned farms where application of fire and grazing is mostly variable (Howell et al. 2009; Hanley et al. 2012; Jacobs et al. 2012; Ciuzio et al. 2013). In these differently managed lands, we suggest that measurements of vegetation variables be limited to grass height and cover because these are the key habitat variables that are mostly associated with habitat use by birds (Fisher and Davis 2010; Hovick et al. 2014) and doing so also allows survey efforts to cover a large area in a short space of time. Finally we suggest that investigation of factors that affect birds density or suitability be based on surveys from inside the farms, rather than counting along roads (e.g. Wellicome et al. 2014). Habitat on road verges often 


\section{Zitting Cisticola}

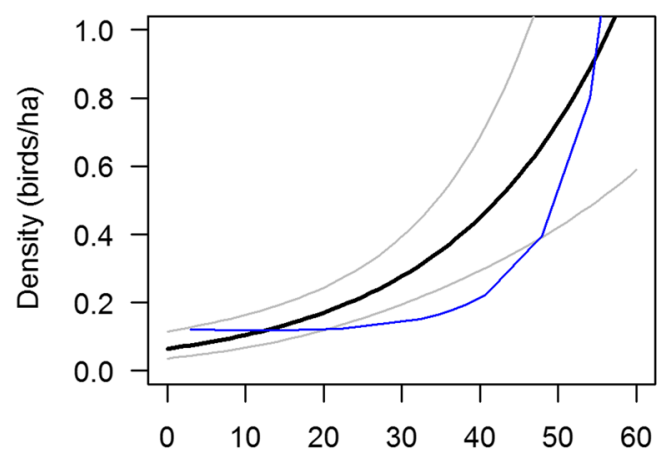

Average grass height $(\mathrm{cm})$

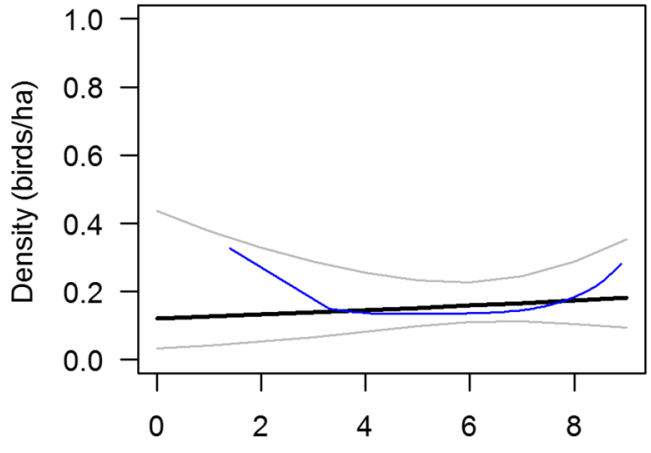

Average grass cover (\# of grids out 9)

\section{Common Quail}

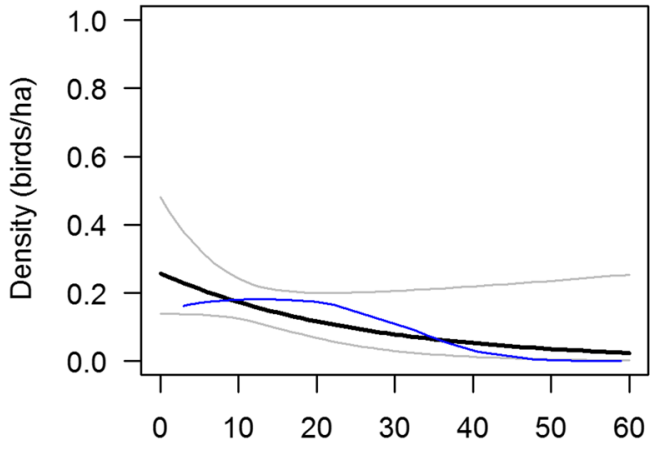

Average grass height $(\mathrm{cm})$

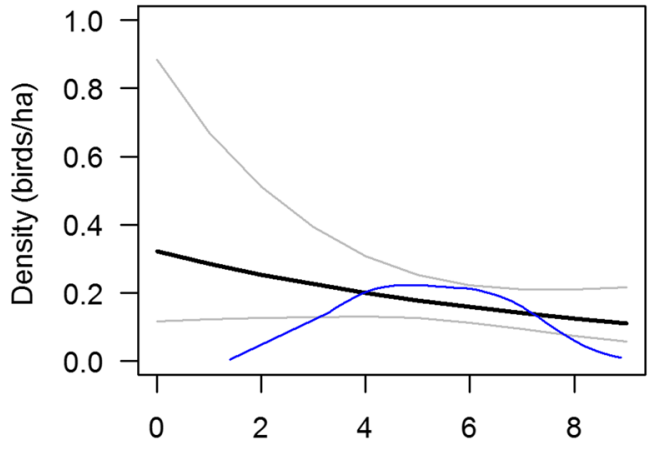

Average grass cover (\# grids out of 9)

Fig. 6 Effect of average grass height and cover on the habitat suitability of Zitting Cisticola and Common Quail at a high-elevation grassland of eastern South Africa. See legend to Fig. 3 for details

does not resemble habitat within farms and birds nesting along road verges may be more exposed to predation (Wellicome et al. 2014) and may suffer more from disturbances.

Our study supports previous suggestions that worldwide fire and grazing complement each other to make habitats suitable for birds (Fuhlendorf et al. 2009). However, the most important proximate habitat variables in grasslands are grass height and cover (Fisher and Davis 2010). These two variables can be managed with fire and grazing to improve habitat suitability for grassland bird communities (Fuhlendorf et al. 2009; Maphisa et al. 2009).

\section{Conclusions}

Grass height and cover were important predictors of density for all eight common grassland species we examined. However, the species reacted to variation in grass height and cover in different ways. Our results therefore suggest that management should aim to provide a mosaic of patches with different grass height and cover to promote habitat suitability for grassland birds in general in the grasslands of eastern South Africa. Combined use of fire and grazing could be used to create such a mosaic, which is likely to benefit rare species, in addition to the common ones we studied. 


\section{Additional files}

Additional file 1: Appendix S1. Negative log likelihood (-Loglike), number of parameters (K), Akaike's Information Criterion (AIC), difference in AIC (Delta AIC) and AIC model weights (AICWt). List of candidate models representing alternative ways to model the detection process for eight grassland bird species. For each species, we selected the best detection model based on lowest AIC value (in bold).

Additional file 2: Appendix S2. Negative log likelihood (-Loglike), number of parameters (K), Akaike's Information Criterion (AIC), difference in AIC (Delta AIC) and AIC model weights (AICwt). List of candidate models used to estimate the influence of burning (Burning), grazing (Grazing), grass height (avh) and grass cover (cover) as linear (on the log scale) relationships or regression splines with two knots (s(avh) and s(cover)) on eight grassland bird species. All models used the best structure for the detection function determined during the analysis presented in table in Additional file 1: Appendix S1.

\section{Authors' contributions}

DHM conceived and designed the field survey methods and carried out the fieldwork. DHM and RA analysed the data, interpreted the results and wrote the paper. HS proofread and made comments to the manuscript, LG commented on the original manuscript draft. All authors read and approved the final manuscript.

\section{Author details \\ 1 South African National Biodiversity Institute, Private Bag X7, Claremont 7735, South Africa. ${ }^{2}$ Statistics in Ecology, Environment and Conservation, Depart- ment of Statistical Sciences, University of Cape Town, Rondebosch 7701, South Africa. ${ }^{3}$ BirdLife South Africa, Private Bag X5000, Parklands 2121, South Africa. ${ }^{4}$ Applied Behavioural Ecological and Ecosystem Research Unit (ABEERU), UNISA, Private Bag X6, Florida 1717, South Africa. ${ }^{5}$ Animal Demography Unit, Department of Biological Sciences, University of Cape Town, Ronde- bosch 7701, South Africa. ${ }^{6}$ African Climate and Development Initiative, University of Cape Town, Rondebosch 7701, South Africa.}

\section{Acknowledgements}

The first author was supported in the position of BirdLife South Africa Ingula Project Manager with funding by Eskom through The Ingula Partnership. The Mazda Wildlife Fund supported the first author with a vehicle for the duration of the project, while employed by BirdLife South Africa. We are greatly indebted to Malcolm Drummond for proofreading the original manuscript. RA was supported by the National Research Foundation of South Africa (Grant 85802). The NRF accepts no liability for opinions, findings and conclusions or recommendations expressed in this publication.

\section{Competing interests}

The authors declare that they have no competing interests.

Received: 23 August 2016 Accepted: 19 January 2017

Published online: 03 March 2017

\section{References}

Alexander B, Hepp G. Estimating effects of habitat characteristics on abundances of three species of secretive marsh birds in Central Florida. Waterbirds. 2014;37:274-85.

Apfelbaum S, Haney A. Bird populations before and after wildfire in a Great Lakes pine forest. Condor. 1981;83:347-54.

Azpiroz AB, Blake JG. Associations of grassland birds with vegetation structure in the Northern Campos of Uruguay. Condor. 2016;1 18:12-23.

Barnes KN. The important bird areas of Southern Africa. Johannesburg: BirdLife South Africa; 1998.

Bibby CJ, Burgess ND, Hill DA, Mustoe S. Bird census techniques. 2nd ed. London: Academic Press; 2000.
Broekema I, Overdyck O. Distance sampling to estimate densities of four native forest bird species during multi-species surveys. N Z J Ecol. 2012;36:1-12.

Buckland S, Burnham KP, Laake J, Borchers D, Thomas L. Introduction to distance sampling. Oxford: Oxford University Press; 2001.

Burnham K, Anderson DR. Model selection and multimodel inference: a practical information-theoretic appraoch. 2nd ed. New York: Springer; 2002.

Carrascal L, Seoane J, Palomino D. Bias in density estimations using strip transects in dry open-country environments in the Canary Islands. Anim Biodivers Conserv. 2009;2:45-50.

Cauldwell A. Second progress report: veld condition assessment for Ingula Pumped Storage Scheme, a report to Eskom Holdings, Megawatt Park, Johannesburg. 2012. p. 1-12.

Ceballos G, Davidson A, List R, Pacheco J, Manzano-Fischer P, Santos-Barrera G, Cruzado J. Rapid decline of a grassland system and its ecological and conservation implications. PLoS ONE. 2010;5(1):e8562.

Ciuzio E, Hohman WL, Martin B, Smith MD, Stephens S, Strong AM, Vercauteren T. Opportunities and challenges to implementing bird conservation on private lands. Wildl Soc Bull. 2013;37:267-77.

Crainiceanu CM, Ruppert D, Wand MP. Bayesian analysis for penalized spline regression using WinBUGS. J Stat Softw. 2005;14:1-24.

Devereux CL, Whittingham MJ, Krebs JR, Fernandez-Juricic E, Vickery JA. What attracts birds to newly mown pasture? Decoupling the action of mowing from the provision of short swards. Ibis. 2006;148:302-6.

Diefenbach D, Brauning D. Variability in grassland bird counts related to observer differences and species detection rates. Auk. 2003;120:1 168-79.

Donald PF, Buchanan GM, Collar NJ, Dellelegn Abebe Y, Gabremichael MN, Mwangi MAK, Ndangángá PK, Spottiswoode CN, Wondafrash M. Rapid declines in habitat quality and population size of the Liben (Sidamo) Lark Heteromirafra sidamoensis necessitate immediate conservation actionERRATUM. Bird Conserv Int. 2010;20:214.

Egoh BN, Reyers B, Rouget M, Richardson DM. Identifying priority areas for ecosystem service management in South African grasslands. J Environ Manag. 2011;92:1642-50.

Fairbanks DHK, Thompson MW, Vink D, Newby T, Van den Berg HM, Everard DA. The South African land-cover characteristics database: a synopsis of the landscape. S Afr J Sci. 2000;96:69-82.

Fisher RJ, Davis SK. From Wiens to Robel: a review of grassland-bird habitat selection. J Wildl Manag. 2010;74:265-73.

Fiske I, Chandler R. unmarked: an R package for fitting hierarchical models of wildlife occurrence and abundance. J Stat Softw. 2011;43:1-23.

Fiske I, Chandler R. Overview of unmarked: an R package for the analysis of data from unmarked animals. 2012. p. 5-10. http://citeseerx.ist.psu. edu/viewdoc/download?doi=10.1.1.230.8806\&rep=rep1\&type=pdf. Accessed 29 Feb 2016.

Fuhlendorf SD, Engle DM, Kerby J, Hamilton R. Pyric herbivory: rewilding landscapes through the recoupling of fire and grazing. Conserv Biol. 2009;23:588-98.

Hanley N, Banerjee S, Lennox GD, Armsworth PR. How should we incentivize private landowners to "produce" more biodiversity? Oxf Rev Econ Policy. 2012;28:93-113.

HovickTJ, Elmore RD, Fuhlendorf SD. Structural heterogeneity increases diversity of non-breeding grassland birds. Ecosphere. 2014;5:1-13.

Howell JE, Moore CT, Conroy MJ, Hamrick RG, Cooper RJ, Thackston RE, Carroll JP. Conservation of northern bobwhite on private lands in Georgia, USA under uncertainty about landscape-level habitat effects. Landsc Ecol. 2009;24:405-18.

Jacobs RB, Thompson FR, Koford RR, La Sorte FA, Woodward HD, Fitzgerald $J$ A. Habitat and landscape effects on abundance of Missouri's grassland birds. J Wildl Manag. 2012;76:372-81.

Jansen R, Little RM, Crowe TM. Implications of grazing and burning of grasslands on the sustainable use of francolins (Francolinus spp.) and on overall bird conservation in the highlands of Mpumalanga province, South Africa. Biodivers Conserv. 1999;8:587-602.

Klug PE, Jackrel SL, With KA. Linking snake habitat use to nest predation risk in grassland birds: the dangers of shrub cover. Oecologia. 2010;162(3):803-13.

Kosicki JZ, Chylarecki P, Zduniak P. Factors affecting Common Quail's Coturnix coturnix occurrence in farmland of Poland: is agriculture intensity important? Ecol Res. 2014;29:21-32. 
Lee AT, Barnard P, Hockey PA. Population metrics for fynbos birds, South Africa: densities, and detection and capture rates from a Mediterranean-type ecosystem. Ostrich. 2015;86:179-87

Lewandowski A. The effectiveness of surrogate taxa for the representation of biodiversity. Conserv Biol. 2010;24:1367-77.

Little I, Hockey PAR, Jansen R. Impacts of fire and grazing management on South Africa's moist highland grasslands: a case study of the Steenkampsberg Plateau, Mpumalanga, South Africa. Bothalia. 2015a;45:1-15.

Little IT, Hockey PA, Jansen R. Predation drives nesting success in moist highland grasslands: the importance of maintaining vegetation cover for bird conservation. Ostrich. 2015b:86:97-111.

Little IT, Hockey PAR, Jansen R. A burning issue: fire overrides grazing as a disturbance driver for South African grassland bird and arthropod assemblage structure and diversity. Biol Conserv. 2013;158:258-70.

Loe LE, Mysterud A, Stien A, Steen H, Evans DM, Austrheim G. Positive short-term effects of sheep grazing on the alpine avifauna. Biol Lett. 2007:3:109-11.

Mamo Y, Mengesha G, Asefa A. Abundance and habitat preference of the near-threatened endemic Abyssinian Long-claw Macronyx flavicollis in the northern montane grasslands of the Bale Mountains, Ethiopia. Int J Dev Res. 2014;6:1887-93.

Mamo Y, Asefa A, Mengesha G. Effects of livestock grazing on an Afromontane grassland bird community in the Bale Mountains of Ethiopia. Afr J Ecol. 2016:54:1-8.

Maphisa D. First reported Africa Grass-Owl Tyto capensis power line mortality at the Ingula Pumped Storage Scheme, South Africa. Gabar. 2012;23:17-21.

Maphisa DH. Towards adaptive management of moist high-altitude grasslands: Ingula as a case study. PhD thesis, University of Cape Town, Rondebosch; 2015.

Maphisa DH, Donald PF, Buchanan GM, Ryan PG. Habitat use, distribution and breeding ecology of the globally threatened Rudd's Lark and Botha's Lark in eastern South Africa. Ostrich. 2009;80:19-28.

Maphisa DH, Smit-robinson H, Underhill LG, Altwegg R. Drivers of bird species richness within moist high-altitude grasslands in eastern South Africa. PLOS ONE. 2016;11:e0162609.

Marnewick M, Retief E, Wright D, Theron N. South Africa's important bird and biodiversity areas status report. Johannesburg: Birdlife South Africa; 2015.

Marques TA, Thomas L, Fancy SG, Buckland ST. Improving estimates of bird density using multiple-covariate distance sampling. Auk. 2007:124:1229-43.

Martin J, Chamaillé-Jammes S, Nichols JD, Fritz H, Hines JE, Fonnesbeck CJ, MacKenzie DI, Bailey LL. Simultaneous modeling of habitat suitability, occupancy, and relative abundance: African elephants in Zimbabwe. Ecol Appl. 2010;20:1173-82.

Marx DE, Hejl SJ, Herring G. Wintering grassland bird habitat selection following summer prescribed fire in a Texas gulf coast tallgrass prairie. Fire Ecol. 2008:4:46-62.

Mattsson BJ, Marshall MR. Occupancy modeling as a framework for designing avian monitoring programs: A case study along Appalachian streams in southern West Virginia. In: Fourth international partners in flight conference: tundra to tropics. 2009. p. 617-32.

Mellin C, Bradshaw CJA, Meekan MG, Caley MJ. Environmental and spatial predictors of species richness and abundance in coral reef fishes. Glob Ecol Biogeogr. 2010;19:212-22.

Mentis MT. Brammhoek Pumped Storage Scheme burning and grazing regimes. A report to Eskom Holdings, Megawart Park. Johannesburg, South Africa; 2006.

Mentis MT. Wetland Specialist report, EIA National Road 3: Keeversfontein to Warden (De Beers Pass section). A report prepared for the South African National Roads Agency Ltd, Pretoria; 2014

Mentis MT, Bigalke RC. The effect of scale of burn on the densities of grassland francolins in the Natal Drakensberg. Biol Conserv. 1981;21:247-61.

Mero TO, Lontay L, Lengyel S. Habitat management varying in space and time: the effects of grazing and fire management on marshland birds. J Ornithol. 2015;156:579-90.

Nally RM, Fleishman E. A successful predictive model of species richness based on indicator species. Conserv Biol. 2004;18:646-54.

O'Connor TG, Kuyler P. Impact of land use on the biodiversity integrity of the moist sub-biome of the grassland biome, South Africa. J Environ Manag. 2009;90:384-95.
Oedekoven CS, Buckland ST, Mackenzie ML, Evans KO, Burger LW. Improving distance sampling: accounting for covariates and non-independency between sampled sites. J Appl Ecol. 2013;50:786-93.

Parr CL, Chown SL. Burning issues for conservation: a critique of faunal fire research in Southern Africa. Austral Ecol. 2003;28:384-95.

Petitot M, Manceau N, Geniez P, Besnard A. Optimizing occupancy surveys by maximizing detection probability: application to amphibian monitoring in the Mediterranean region. Ecol Evol. 2014;4:3538-49.

Post van der Burg M, Bly B, VerCauteren T, Tyre AJ. Making better sense of monitoring data from low density species using a spatially explicit modelling approach. J Appl Ecol. 2011;48:47-55.

R Development Core Team. R: a language and environment for statistical computing. Vienna: R Foundation for Statistical Computing; 2013. http:// www.R-project.org/.

Reyers B. Priority areas for the conservation of South African vegetation: a coarse-filter approach. Divers Distrib. 2001;7:79-95.

Richardson AN, Koper N, White KA. Interactions between ecological disturbances: burning and grazing and their effects on songbird communities in northern mixed-grass prairies. Avian Conserv Ecol. 2014;9:5.

Royle JA, Dawson DK, Bates S. Modeling abundance effects in distance sampling. Ecology. 2004;85:1591-5.

Sillett ST, Chandler RB, Royle JA, Kéry M, Morrison SA. Hierarchical distance sampling models to estimate population size and habitat-specific abundance of an island endemic. Ecol Appl. 2012;22:1997-2006.

Speed JDM, Austrheim G, Hester AJ, Mysterud A. Experimental evidence for herbivore limitation of the treeline. Ecology. 2010;91:3414-20.

Taillie PJ, Peterson MN, Moorman CE. The relative importance of multiscale factors in the distribution of Bachman's Sparrow and the implications for ecosystem conservation. Condor. 2015:117:137-46.

Taylor M, Peacock F, Wanless R. The 2015 Eskom Red Data Book of Birds of South Africa, Lesotho and Swaziland. Taylor M, Peacock F, Wanless R, editors. Johannesburg: BirdLife South Africa; 2015.

Thomas L, Buckland ST, Rexstad EA, Laake JL, Strindberg S, Hedley SL, Bishop JRB, Marques TA, Burnham KP. Distance software: design and analysis of distance sampling surveys for estimating population size. J Appl Ecol. 2010;47:5-14

Thomas L, Laake JL, Strindberg S, Marques FFC, Buckland ST, Borchers DL, Anderson DR, Burnham KP, Hedley SL, Pollard JH. DISTANCE, version 5.0, beta 5. Research Unit for Wildlife Population Assessment, University of St. Andrews. 2005. p. 544-52.

Weller F, Blackwell G, Moller H. Detection probability for estimating bird density on New Zealand sheep \& beef farms. N Z J Ecol. 2012;36:1-11.

Wellicome T, Kardynal K, Franken R, Gillies C. Off-road sampling reveals a different grassland bird community than roadside sampling: implications for survey design and estimates to guide conservation. Avian Conserv Ecol. 2014;9(1):4.

Winter M, Johnson DH, Shaffer JA. Variability in vegetation effects on density and nesting success of grassland Birds. J Wildl Manag. 2005;69:185-97.

Wintle BA, Elith J, Potts JM. Fauna habitat modelling and mapping: a review and case study in the Lower Hunter Central Coast region of NSW. Austral Ecol. 2005;30:719-38.

With KA, King AW, Jensen WE. Remaining grasslands may not be sufficient to prevent grassland bird declines. Biol Conserv. 2008;141:3152-67.

\section{Submit your next manuscript to BioMed Central and we will help you at every step:}

- We accept pre-submission inquiries

- Our selector tool helps you to find the most relevant journal

- We provide round the clock customer support

- Convenient online submission

- Thorough peer review

- Inclusion in PubMed and all major indexing services

- Maximum visibility for your research

Submit your manuscript at www.biomedcentral.com/submit 